\title{
Smart Parking System Using IoT
}

\author{
Dr. K Madhavi', Naveen Kandulu², Ravada Mohan Rao ${ }^{3}$, Susmitha Manimala Vandrasi ${ }^{4}$, Gonthina Kumar Swamy ${ }^{5}$ \\ Associate Professor, Department of Computer Science and Engineering, NSRIT, Visakhapatnam, India ${ }^{1}$. \\ Student, Department of Computer Science and Engineering, NSRIT, Visakhapatnam, India ${ }^{2,3,4,5}$
}

\begin{abstract}
Parking problems are very much common in most of the major cities of any country. The narrow accessibility of parking results in traffic blocking, air effluence as well as driver frustration. The price for parking extension is frequently unaffordable or enormously high. Recently investigators turned to apply technologies for effective parking administration. It is understood that this simple development could be applied to monitor vehicles in parking spaces can be executed. In this arrangement, the driver can get the position of the parking slot through the website. The system can then notify drivers for the number of accessible parking spaces. The system should be achieved over the less network circulation and diminish the database server disruptions preserving the organization in the client data fast and precise response. The system should apply to large and small areas. The system should provide reliable performance.
\end{abstract}

Keywords: database, IoT, technologies, performance

\section{Introduction}

Nowadays parking is a big problem in the major cities the expansion of the parking slot is impossible an finding the free parking slots in open parking tougher. So there are many systems by using the technologies provided the efficient parking management but the existing systems use the brute force method to perform this activity. On a device will update the data int the database and the client device is continuously requesting the updated data on the database server which leads to the more amount of load on the database server. The network traffic increased and the data on the clients will not in the synchronized manner. For those problems, there is a solution called the firebase real-time database. The Firebase Realtime Database is cloud-hosted. Data is stored as JSON and synchronized in real-time to every connected client. There will be a module built out by node MCU and the ultrasonic sensor which is used to update the status of the parking slot to the firebase. When the change in the data of the Realtime Database, all of your clients share one Realtime Database instance and automatically receive updates with the newest data. In this model, the client device doesn't need to interrupt the database server continuously. When the change occurs the client will receive the data so less network usage. as the equipment is small as it provides a portable feature which supports to use in the open area parking. the devices are individual bodies so it supports use as our requirement those can be used for large and small scale areas.

\section{Block diagram}

Architechture of smart parking system

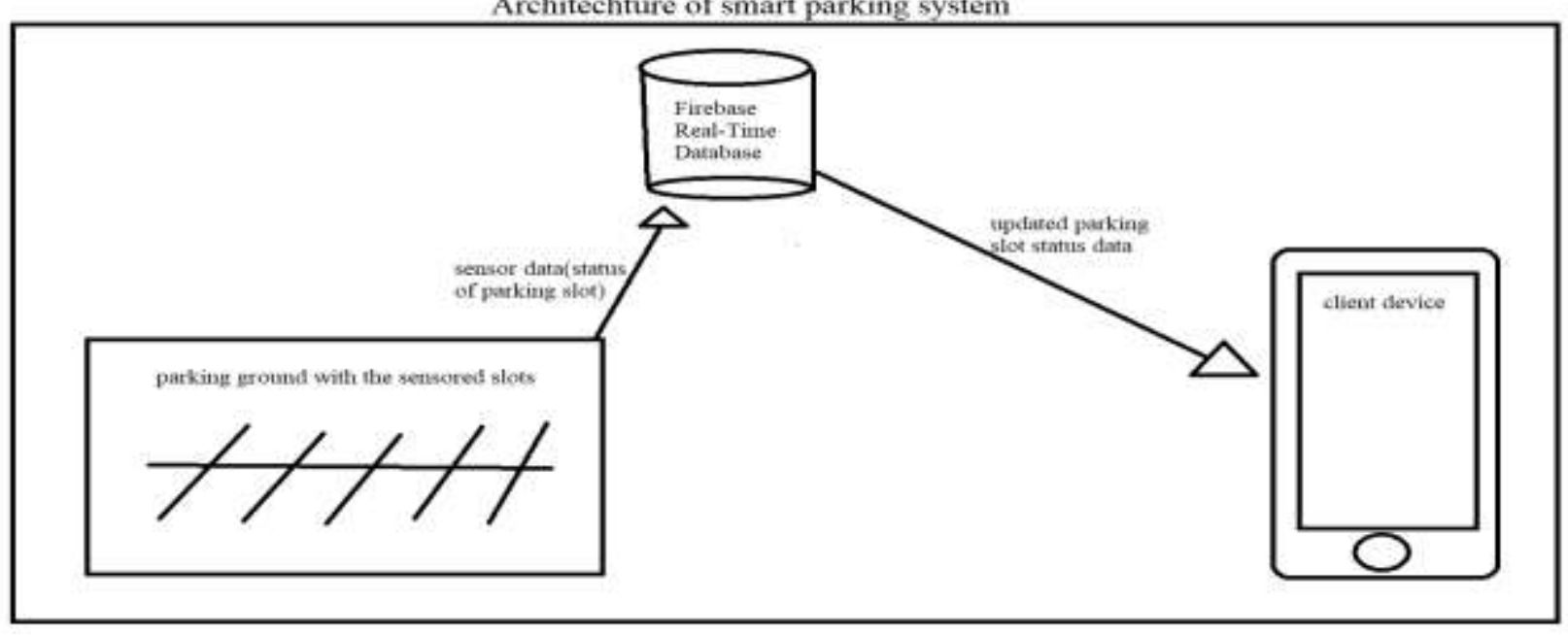

\section{Requirements}

\section{Hardware requirement}

\section{NodeMCU}

NodeMCU V3 is an open source firmware \& development kit that shows an important character in planning an IoT product with a few writing lines. Various GPIO pins on the board allows us to link the board with other peripherals. This capability to read the ultrasonic data with the help of the ESP8266 Wi-Fi SoC can connect with the internet and send the data to the firebase.

\section{Ultrasonic sensor}


An ultrasonic sensor is a power-driven device that procedures the distance of a goal element by discharging ultrasonic sound waves $\&$ interprets the reproduced sound into an electrical signal. Ultrasonic waves travel quicker than the rapidity of noticeable sound (the sound that individuals can catch). Ultrasonic sensors have mainly two workings: the spreader (which produces the sound via piezoelectric crystals) \& the receiver (which run into the sound after it has traveled to \& from the goal).

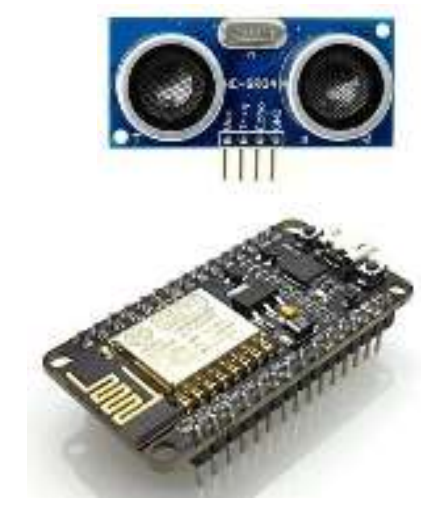

\section{Software requirement}

\section{Firebase real-time database}

The Firebase Realtime Database is cloud-hosted. Data is stored as JSON and synchronized in real-time to every connected client. When the change in the data of the Realtime Database, all of your customers share one Realtime Database occurrence \& inevitably obtain updates with the latest data.

\section{Key capabilities}

\section{Real-time}

As an alternative of typical HTTP appeals, the Firebase Real time Database performs data association - every time data variations, any linked device obtains that apprise within no time. Provide concerted \& immersive involvements without thinking about the interacting code.

\section{Offline}

Firebase apps endure approachable even whenever it is offline since the Firebase Real time Database SDK perseveres your statistics to disk. Once connectivity is reinvented, the client device attains any adjustments it lost, coordinating it with the current server state.

\section{Accessible from Customer Devices}

The Firebase Real time Database can be retrieved openly from any of the device or any of the web browser; there is no necessity for submission server. Security \& data authentication are accessible over the Firebase Real time Database Safety Rules, expressionbased instructions that are implemented when statistics is deliver or written

\section{Web technologies}

The programing knowledge required to build a webpage like HTML, CSS, JavaScript. Some knowledge on working with the JSON objects and JSON format data. 


\section{Results}

Data of available slots

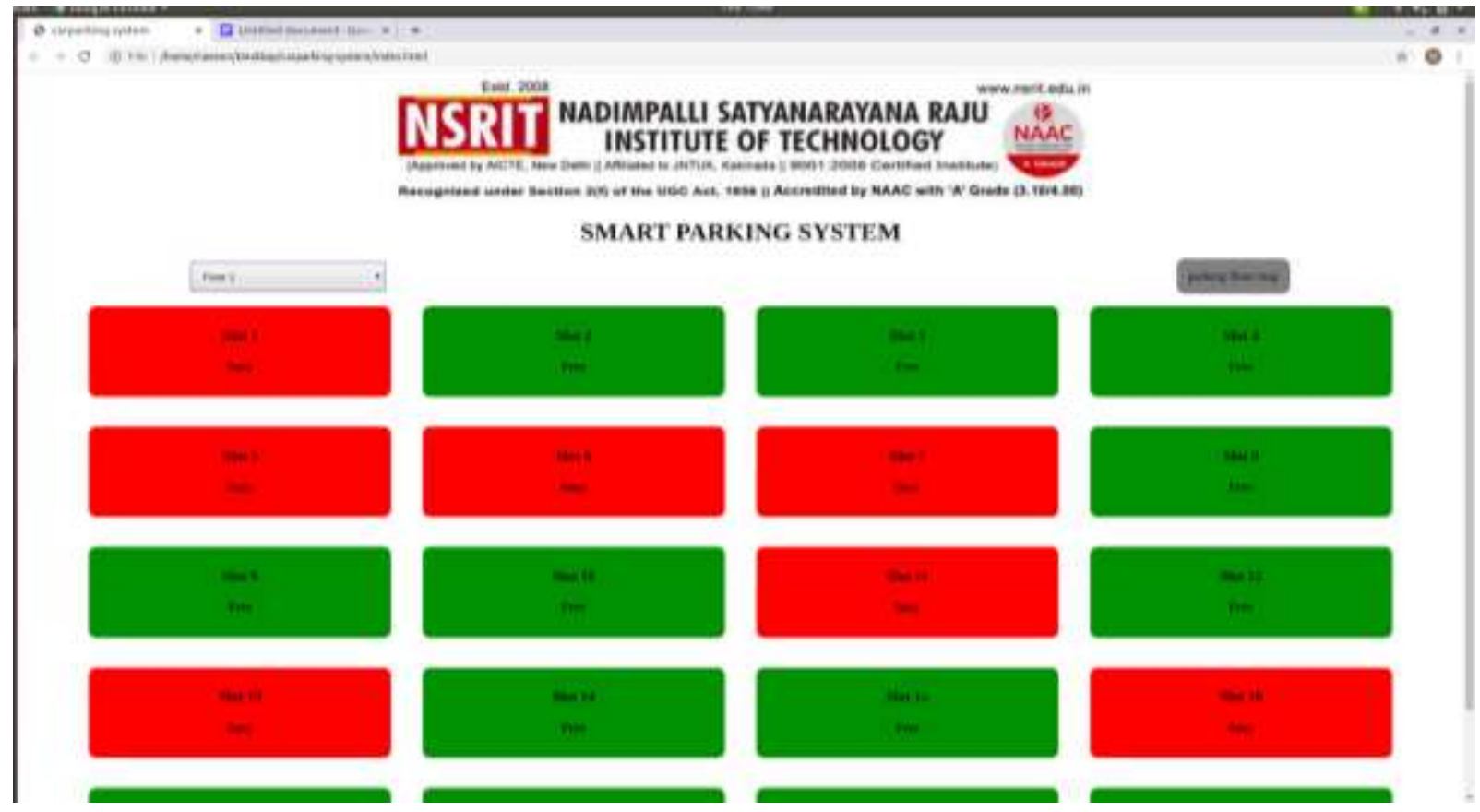

Map of slots

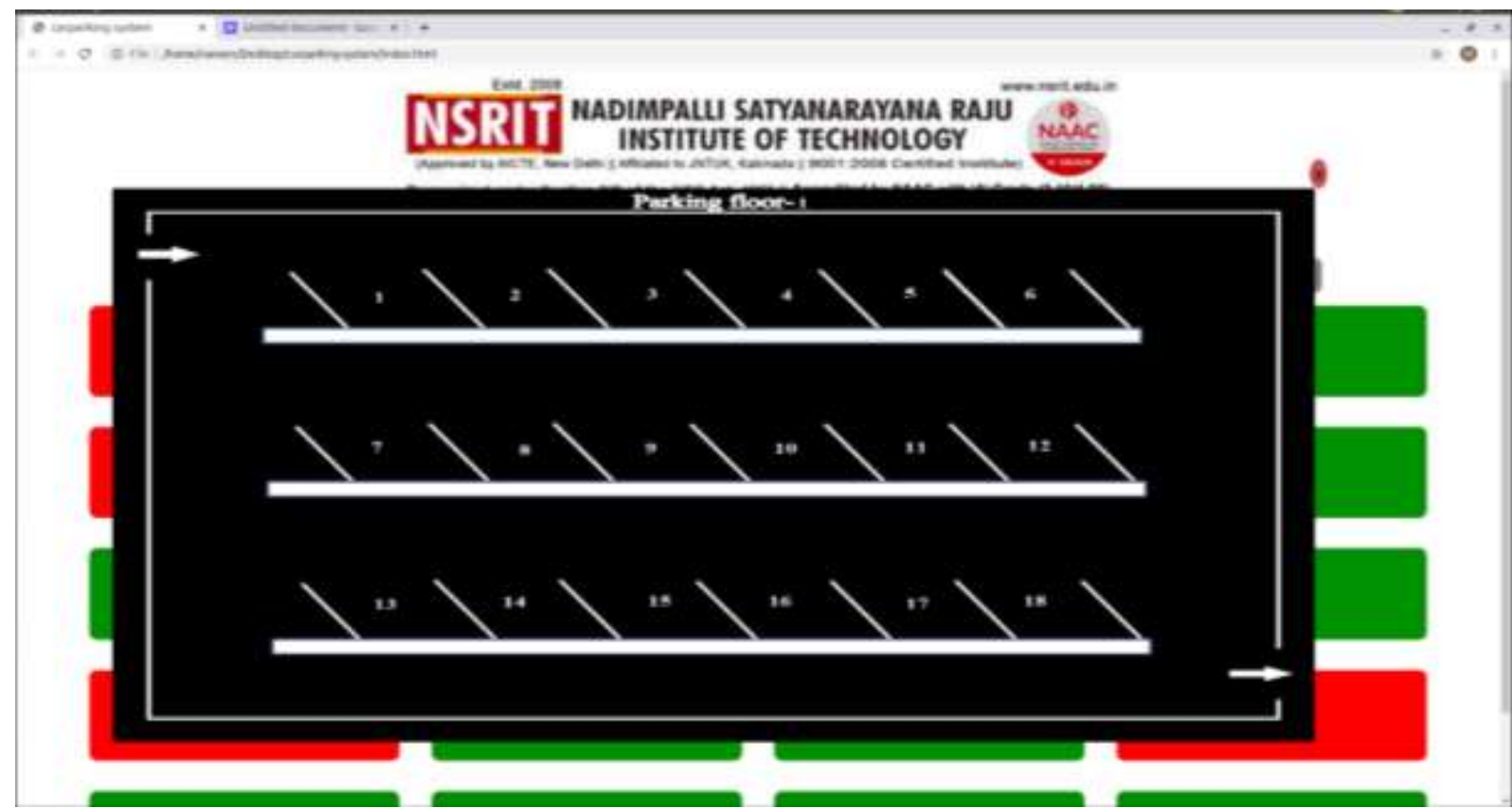

\section{Conclusion}

In this project, we are presented and advance improvements to the existing system the can be implemented right now with the technical advancement. in my project, I used a fire base real time database to send the data to the client when the parking slot is changed over the website. by that, the database server load will be reduced and network traffic is minimized. a reliable consistent system can be created.

\section{Future Scope}

In the future, we would like to add the slot reservation feature with the location-based system, and we will suggest the nearest and available slot for the driver if he ok with it he can reserve the solve and he will directly navigate to that slot. 


\section{References}

[1] J. Rico, J. Sancho, B. Cendon, M. Camus, "Parking easier by using context information of a smart city: Enabling fast search and management of parking resources", Advanced Information Networking and Applications Workshops (WAINA) 2013 27th International Conference on, pp. 1380-1385, 2013, March.

[2] Y. Zheng, S. Rajasegarar, C. Leckie, "Parking availability prediction for sensor-enabled car parks in smart cities", Intelligent Sensors Sensor Networks and Information Processing (ISSNIP) 2015 IEEE Tenth International Conference on, pp. 1-6, 2015, April.

[3] F. Zhou, Q. Li, "Parking Guidance System Based on ZigBee and Geomagnetic Sensor Technology", Distributed Computing and Applications to Business Engineering and Science (DCABES) 2014 13th International Symposium on, pp. 268-271, 2014, November.

[4] A. Botta, W. De Donato, V. Persico, A. Pescapé, "On the Integration of Cloud Computing and Internet of Things", Future Internet of Things and Cloud (FiCloud) 2014 International Conference on, pp. 23-30, 2014, August.

[5] A. Zaslavsky, C. Perera, D. Georgakopoulos, "Sensing as a service and big data", arXiv preprint arXiv: 1301.0159, 2013.

[6] C. Doukas, L. Capra, F. Antonelli, E. Jaupaj, A. Tamilin, I. Carreras, "Providing generic support for IoT and M2M for mobile devices", Computing \& Communication Technologies-Research Innovation and Vision for the Future (RIVF) 2015 IEEE RIVF International Conference on, pp. 192-197, 2015, January.

[7] C. Tsirmpas, A. Anastasiou, P. Bountris, D. Koutsouris, "A new method for profile generation in an Internet of Things environment: An application in ambient assisted living.

[8] G. Suciu, A. Vulpe, S. Halunga, O. Fratu, G. Todoran, V. Suciu, "Smart cities built on resilient cloud computing and secure internet of things", Control Systems and Computer Science (CSCS) 2013 19th International Conference on, pp. 513-518, 2013, May.

[9] S. K. Dash, S. Mohapatra, P. K. Pattnaik, "A survey on applications of wireless sensor network using cloud computing", International Journal of Computer science \& Engineering Technologies (E-ISSN: 2044-6004), vol. 1, no. 4, pp. 50-55, 2010.

\section{Author Details}

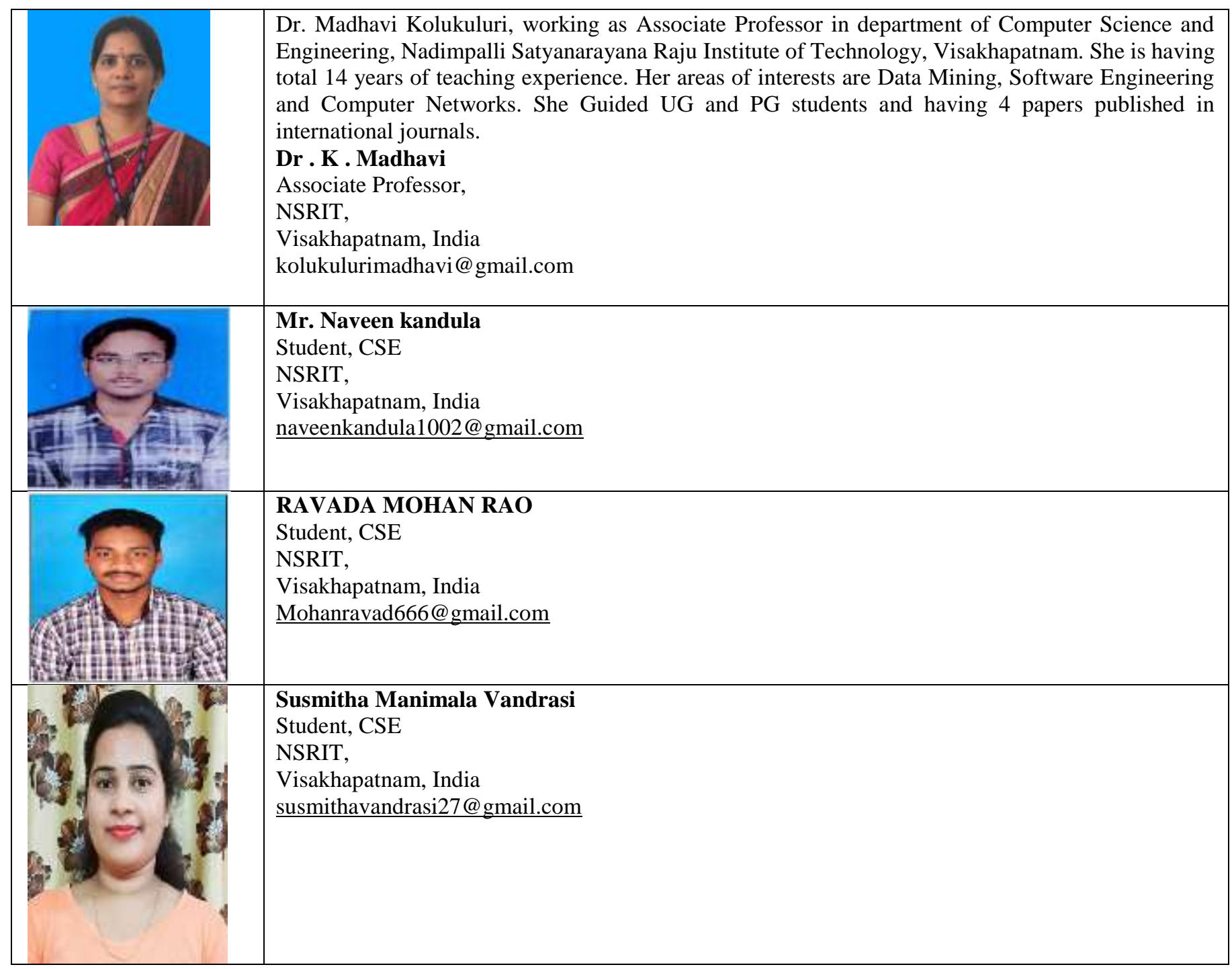




\begin{tabular}{|l|l|}
\hline & Gonthina kumar swamy \\
& \\
& Student, CSE \\
NSRIT, \\
Visakhapatnam, India \\
Kumarswamy1616@gmail.com \\
\hline
\end{tabular}

